\title{
Adjunctive behavior in multiple schedules of reinforcement
}

\author{
PATRICIA A. HAIGHT and PETER R. KILLEEN \\ Arizona State University, Tempe, Arizona
}

\begin{abstract}
A recent theory of timing (Killeen \& Fetterman, 1988) suggests that adjunctive behaviors may act as discriminative cues for the passage of time and that the rate of transition between those behaviors is affected by the rate of reinforcement within the experimental context. Is the rate of transition between behaviors correlated with the rate of reinforcement? What is the context in which rate of reinforcement is calibrated? If rate of transition is correlated with reinforcement frequency, does this correlation change with extended training? Four pigeons were trained on multiple fixed-time schedules of reinforcement, with one component always FT 15 sec, the other either FT $15 \mathrm{sec}$, FT $45 \mathrm{sec}$, or FT $5 \mathrm{sec}$. Behavior was coded into one of 12 categories. Response distributions in the constant component shifted when rate of reinforcement was varied in the other component and eventually shifted back toward their original location.
\end{abstract}

Animals trained on reinforcement schedules in which food is presented at fixed intervals develop repetitive and stereotyped behaviors (Anderson \& Shettleworth, 1977; Reberg, Innis, Mann, \& Eizenga, 1978; Staddon \& Simmelhag, 1971). These patterns of behavior vary among animals but remain consistent within individuals (Haight, 1989). Such responses frequently are divided into the distinct classes of interim and terminal behaviors (Staddon \& Simmelhag, 1971). Interim responses occur immediately after food delivery and persist throughout the first portion of the interfood interval. Terminal responses occur in the latter portion of the interval and frequently continue until interrupted by food reinforcement. Equation 1 provides a good description of the distribution of adjunctive behaviors throughout the interval between reinforcers (Killeen, 1979).

Many theories of timing posit pacemaker-accumulator systems to account for temporal judgments. For example, Church (1984) proposed a model in which an internal clock acts as an information processing system that contains specific components such as a pacemaker for generating pulses, a switch connecting the pacemaker to an accumulator, a working (short-term) and a reference (long-term) memory. Pulses continue to accumulate as long as the animal is timing a stimulus. Temporal judgments are made by comparing the number of pulses accumulated with the number of pulses stored in reference memory. Gibbon (e.g., 1986) elaborated a mathematical model called the scalar expectancy theory (SET) that added precision to this framework. Killeen and Fetterman

This research was supported by National Institute of Mental Health (NIMH) Grant RO1 MH43233 to Peter Killeen. We thank J. G. Fetterman for helpful comments on an earlier version of this manuscript and Glenn Ward and Robert Smart for their valuable assistance in collecting data. Requests for reprints should be addressed to Peter Killeen, Department of Psychology, Arizona State University, Tempe, AZ 85287-1104.
(1988) proposed an alternate pacemaker-accumulator theory of timing in which elicited behaviors mediate temporal judgments. According to their behavioral theory (BeT) of timing, animals engage in a sequence of adjunctive behaviors and such behaviors may serve as discriminative cues for the passage of time. Transitions between behaviors are initiated by pulses from an internal pacemaker. If the time between pulses is exponentially distributed, the probability of being in any particular state at time $t$ is described by the density function of the Poisson distribution:

$$
p[N(t)=n]=\frac{(t / \tau)^{n} e^{-t / \tau}}{n !},
$$

in which $\tau$ is the average time spent in a behavioral state and $n$ is the expected number of pulses (previous states) at time $t$. Fetterman and Killeen (1991) and Killeen (1991) review the applications of this model in some detail. Equation 1 is a "worst-case" scenario, as it posits a very unreliable pacemaker. Most plausible biological pacemakers would have a more informative distribution of pulses than the exponential. But Equation 1 provides a convenient special case that is adequate for the present analysis.

BeT takes the mechanism underlying temporal discriminations to be a series of conditional discriminations based on the behaviors that occur at different points in the interfood interval. When an animal judges time spent in an interval, it will respond "short" or "long" based on its observation of its current behavior. Furthermore, it is assumed that the rate of the pacemaker $(1 / \tau)$ varies with the prevailing reinforcement frequency. The current study addressed three questions in reference to BeT. First, what is the environmental context within which the clock is calibrated? Is it the overall rate of reinforcement within an environment, or is it tied to rates within some subset of that environment? Second, does the rate of the pace- 
maker, as inferred from the rate of transition between behaviors, change as a function of reinforcement frequency? Third, if the rate of the pacemaker changes with rate of reinforcement, does the animal adjust to this alteration by adjusting ("recalibrating") the number of pulses required to shift into any particular response state?

We addressed these questions by using a responseindependent, two-component multiple fixed-time fixedtime (mult FT FT) schedule. Typically, such procedures are programmed in the following manner: Two independent schedules of food reward alternate and are signaled by different key colors. With such a design, the reinforcement context may be conceptualized in two ways: First, if reinforcement frequency is averaged over both components ("global averaging"), the contextual rate is simply the (weighted) average of those in each component. On the other hand, context may be defined locally such that its rate of reinforcement is correlated with the programmed reinforcement frequency in that stimulus alone.

The first alternative should not be interpreted as assuming that the animal cannot discriminate two reinforcement frequencies. The question is whether the speed of the pacemaker is based on global or local rates of reinforcement; if the former, the speed of the pacemaker may itself act as the internal standard for discriminating different frequencies of reinforcement. For example, if food comes sooner than "expected," based on the speed of the (global) pacemaker (e.g., food is delivered during an interim behavior rather than a terminal behavior), the animal treats that component as having a higher density of reinforcement than the alternate component. Since pacemaker speed is an "adaptation level" metric of the average rate of reinforcement, discrimination of reinforcement density would be relative to the average density in that environment. Such dependence of discriminability on overall rates of reinforcement is manifest in relativistic laws of behavior, such as Weber's law, the matching law, and scalar timing.

If the first (global) view of calibration context is correct, then as the rate of reinforcement in one component is varied, there should be a correlated change in the rate of the pacemaker, and consequently in the temporal distribution of behaviors in the unchanged component. If the second (local) view of calibration context is correct, then there should be no effect on the distribution of behaviors in the unchanged component, other than perhaps in their levels (rates) because of well-known contrast effects.

\section{METHOD}

\section{Subjects}

The subjects were four male pigeons (Columba livia) maintained at $80 \%$ of their free-feeding weights. Two animals had previous experimental histories (Birds S1 and S3), and two were experimentally naive (Birds S2 and S4). The animals were housed individually in stainless steel cages and maintained on a 12-h light:12-h dark cycle with lights on from 0800 to $2000 \mathrm{~h}$.

\section{Apparatus}

A Plexiglas panel covered with reflective Mylar film replaced the door of a standard two-key Lehigh Valley Electronics operant conditioning chamber ( $28 \mathrm{~cm}$ wide $\times 33 \mathrm{~cm}$ deep $\times 32 \mathrm{~cm}$ high). The right response key was transilluminated with a red or green light to signal the reinforcement frequency in effect. Observational data were collected on a computer placed directly in front of the experimental chamber. White noise and a ventilating fan on the chamber served to mask extraneous noise.

\section{Procedure}

Training. The animals were trained in three conditions. During Condition 1, a response-independent, mult FT 15-sec FT 15-sec schedule was presented in which individual components strictly alternated. These components were signaled by transilluminating the right keylight either red or green. Animals were trained for a minimum of 75 sessions during this baseline condition. In the next condition, Animals $S 1$ and $S 2$ were assigned to a mult FT 15-sec FT 5-sec schedule and Animals S3 and S4 were assigned to a mult FT 15-sec FT 45-sec schedule in which a red keylight signaled the 15-sec component and a green keylight signaled the changed component. These conditions were in force for 55 sessions. During the final condition, schedules in the green component were reversed, so that food was scheduled on an FT 45-sec schedule for Animals S1 and S2 and on an FT 5-sec schedule for Animals S3 and S4. Twenty-four reinforcers consisting of $2 \mathrm{sec}$ of access to grain were delivered during each experimental session for 15 sessions.

Response description and scoring. Eighteen response categories were determined on the basis of initial observations during habituation and subsequent sessions. Twelve of these proved useful in the subsequent experiments and are listed in Table 1. Responses were differentiated by the data-collection program into orientation and discrete response states. Orientation of the animal was treated as a continuous state and incremented automatically every $.2 \mathrm{sec}$ until another location was recorded. A discrete response was defined as one that occurs in segmented countable units, such as keypecking. Data were stored in 1 -sec time bins. Behavior was recorded by one of two observers. Reliability data were collected by both observers simultaneously recording certain observation periods for 2 subjects. Calculations of reliability (Pearson $r$ correlations of all cells of the time [15] $\times$ behavior [18] matrix; Hartman, 1977) were above .95 .

\section{RESULTS}

\section{Nature of Adjunctive Behaviors in Multiple Schedules}

The purpose of the first condition was to establish a baseline rate of the pacemaker, to determine if stable patterns of behavior developed in both components of the multiple schedule, and to examine the topography and temporal distribution of these behaviors. The patterns of behavior were remarkably similar in both components. The behaviors and their temporal distribution are shown in the top panels of Figure 1 for Animals S1 and S2 and Figure 2 for Animals S3 and S4. Data are plotted by 1-sec time intervals and averaged over the last five sessions of baseline, the second five sessions of shift, and the second five sessions of reversal.

The animals developed patterns of interim and terminal behaviors that were virtually identical in both components. For example, Animal S2 developed a sequence of turning early in the interval, accompanied by several low-frequency behaviors such as neck extension and head turn. The terminal behaviors included orientation to the front wall accompanied by a response in which the bird 
Table 1

Behavior Categories and Descriptions

\begin{tabular}{|c|c|c|}
\hline Response Label & Behavior & Description \\
\hline $\begin{array}{l}\text { Orientation } \\
\text { Front }\end{array}$ & Front (magazine) wall & $\begin{array}{l}\text { Direct body toward the wall containing } \\
\text { the food magazine }\end{array}$ \\
\hline Rgt & Right (window) wall & $\begin{array}{l}\text { Direct body toward the Plexiglas front } \\
\text { panel }\end{array}$ \\
\hline F/R & Intersection of front and right wall & $\begin{array}{l}\text { Position body at the corner in which } \\
\text { magazine wall and Plexiglas front panel } \\
\text { intersect (right corner of chamber) }\end{array}$ \\
\hline $\begin{array}{l}\text { Discrete Response } \\
\text { Trn }\end{array}$ & Turn & $\begin{array}{l}\text { Rotate body and feet at least } 45^{\circ} \text { to the } \\
\text { left or right }\end{array}$ \\
\hline Nck & Neck extension & Neck is extended upward \\
\hline Pck & General pecking & $\begin{array}{l}\text { Pecking responses directed at anything but } \\
\text { the response key }\end{array}$ \\
\hline Crch & Crouch & $\begin{array}{l}\text { A crouching motion in front of the food } \\
\text { magazine, generally accompanied by } \\
\text { magazine wall pecking }\end{array}$ \\
\hline Wlk & Walk & $\begin{array}{l}\text { A sidestepping motion to the left or right } \\
\text { along a chamber wall }\end{array}$ \\
\hline HdT & Head turn & $\begin{array}{l}\text { Any discrete movement of the head left, } \\
\text { right, up, or down }\end{array}$ \\
\hline Jmp & Jump & $\begin{array}{l}\text { A response in which both feet raised off } \\
\text { the floor; this behavior occurred with } \\
\text { wingflapping and appeared to be a flying } \\
\text { movement and was unique to Bird S4 }\end{array}$ \\
\hline Wng & Wing lift & An up and down movement of the wings \\
\hline KP & Keypeck & $\begin{array}{l}\text { Pecking directed at the illuminated right } \\
\text { response key }\end{array}$ \\
\hline
\end{tabular}

assumed a low crouching position and pecked directly above the food hopper. This sequence occurred in both components of the multiple schedule and at approximately the same temporal locations.

\section{Rate of the Pacemaker and its Relation to Rate of Reinforcement}

The second question we asked was whether the speed of transition between behaviors in the red 15-sec component would change when rate of reinforcement was changed in the green component. Such a change would support the hypothesis that the rate of the pacemaker is governed by the rate of reinforcement averaged over the entire experimental context.

Table 2 shows the direction in which each of the recorded behaviors changed over conditions. A leftpointing arrow indicates a shift to the left-the animals entered the state earlier than in the previous condition. Most of the arrows are aligned with the direction predicted by the global hypothesis. Almost all deviation came from Animals S3 and S4 when first shifted to FT 45 sec.

In making our calculations, we used the average halflife of each behavior as the measure of pacemaker rate. The half-life is the time required after the delivery of food for any class of behaviors to reach a rate equal to half its maximal rate, and thus indicates the average time at which animals enter that response state. If the number of pulses required to enter a state does not change, then half- life (HL) will be proportional to $\tau$ : HL $=\tau(n+1)$. This analysis was performed for each behavior in the red component over five session blocks. The mean $\mathrm{HL}$ of all behaviors was then calculated for each block (Table 3 ).

It is our hypothesis that-at least within components of a multiple schedule-all behaviors are in tune with a single pacemaker and differentiate themselves in terms of the number of pulses that are characteristically associated with entry into their states. A direct test of this hypothesis would be to set $\tau$ at a common optimal value, determine the number of counts and scale factors characteristic of each behavior, hold these parameters constant for the shift and reversal data, and determine the direction and extent of the change in $\tau$. This was our original plan. However, when rates of reinforcement were changed, some (but not all) of the scale factors also changed, as would be expected if there were contrast effects. Furthermore, it was clear that the number of counts before switching a state did not stay constant for some behaviors, and holding it constant would distort the interpretation of the data. We had expected the number of counts to eventually change to compensate for the forced change in $\tau$, as they did. But it appears that the shifts in criterion started soon after, and blended with, the shifts in $\tau$.

Since the number of counts associated with a state did not stay constant, it raises questions about our interpretation of the half-life index. Because of these difficulties in data analysis, our report becomes primarily a descrip- 

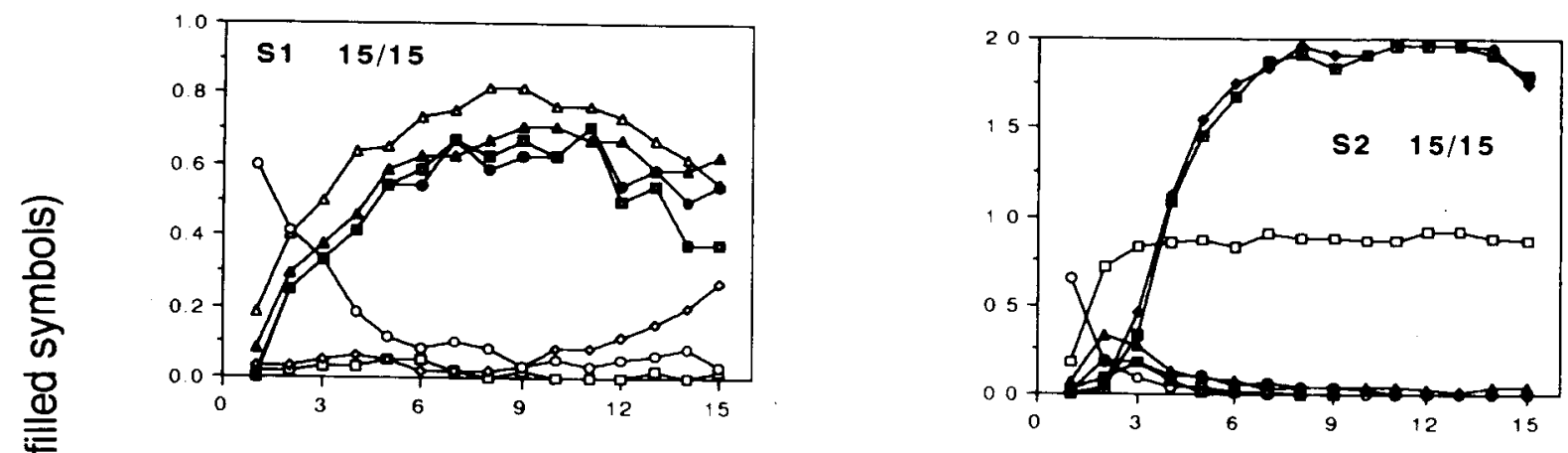

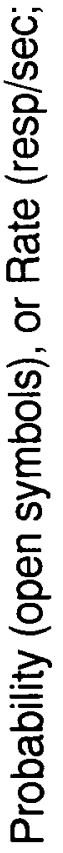
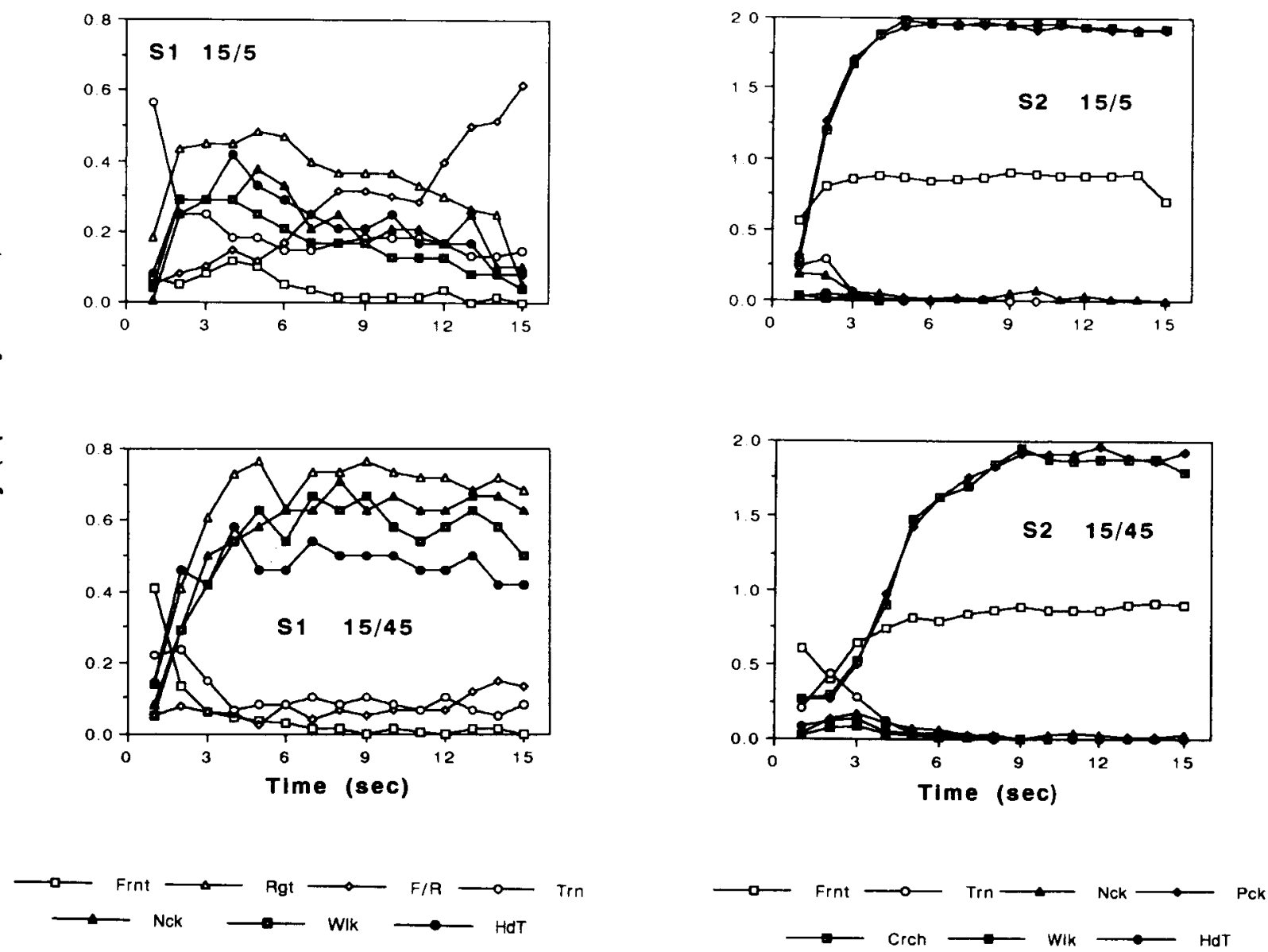

Figure 1. Temporal distribution of adjunctive behaviors for Animals S1 and S2 plotted over 1-sec intervals in the unchanged (15-sec) components of the multiple schedule. Data are averaged over five session blocks. 

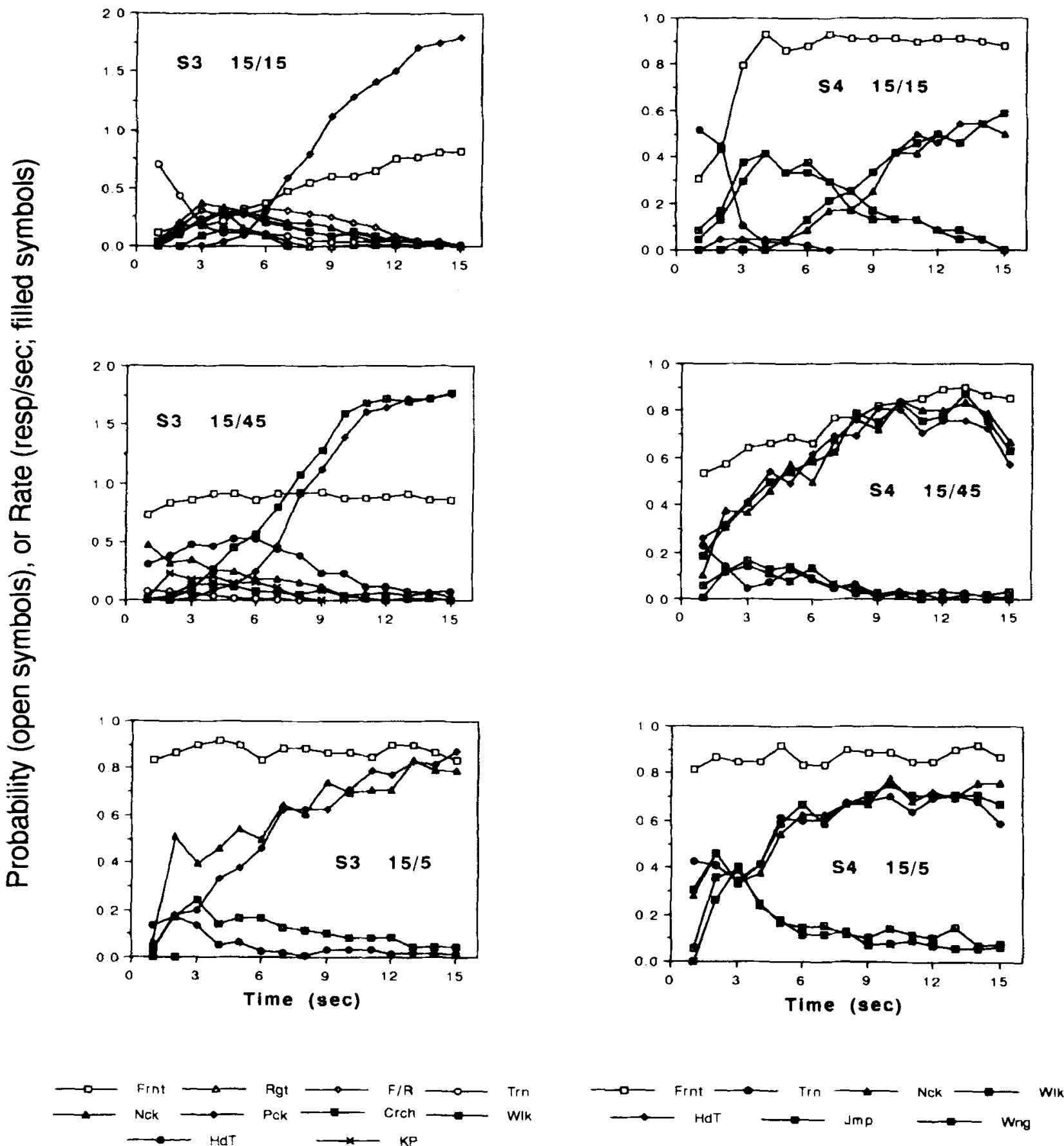

Figure 2. Temporal distribution of adjunctive behaviors for Animals S3 and S4 plotted over 1-sec intervals in the unchanged (15-sec) components of the multiple schedule. Data are averaged over five session blocks. 
Table 2

Direction of Shifts in Distribution of Behaviors in Red (Unchanged) Components

\begin{tabular}{|c|c|c|c|c|c|c|c|c|}
\hline \multirow[b]{3}{*}{ Condition: } & \multicolumn{8}{|c|}{ Animal } \\
\hline & \multicolumn{2}{|c|}{ S1 } & \multicolumn{2}{|c|}{ S2 } & \multicolumn{2}{|c|}{ S3 } & \multicolumn{2}{|c|}{ S4 } \\
\hline & 5 & 45 & 5 & 45 & 45 & 5 & 45 & 5 \\
\hline $\begin{array}{l}\text { Global prediction } \\
\text { Orientation }\end{array}$ & $<$ & $>$ & $<$ & $>$ & $>$ & $<$ & $>$ & $<$ \\
\hline $\begin{array}{l}1 \text { Front } \\
3 \text { Right }\end{array}$ & $\begin{array}{l}< \\
<\end{array}$ & $\begin{array}{l}> \\
>>\end{array}$ & $<$ & $>$ & $<$ & $<$ & $<$ & $<$ \\
\hline $\begin{array}{l}6 \text { Tum } \\
\text { Response }\end{array}$ & & & $>$ & $>$ & $>$ & $<$ & $>$ & $<$ \\
\hline $\begin{array}{l}9 \text { Neck ext } \\
10 \text { Peck } \\
11 \text { Crouch }\end{array}$ & $<$ & $>$ & $\begin{array}{l}< \\
< \\
<\end{array}$ & $\begin{array}{l}> \\
>\end{array}$ & $\begin{array}{l}> \\
< \\
>\end{array}$ & $\begin{array}{l}< \\
< \\
<\end{array}$ & $<$ & $<$ \\
\hline 12 Walk & $<$ & $>$ & & & $<$ & $<$ & $<$ & $<$ \\
\hline $\begin{array}{l}13 \text { Head turn } \\
14 \text { Jump } \\
15 \text { Wing lift }\end{array}$ & $<$ & $<$ & $<$ & $>$ & $<$ & $<$ & $\begin{array}{l}< \\
>\end{array}$ & $\begin{array}{l}< \\
< \\
<\end{array}$ \\
\hline
\end{tabular}

Note $-<=$ Shifts to left; $>=$ shifts to right.

Table 3

Average Half-life (in Seconds) Cakulated Over Five Session Blocks for Each Animal

\begin{tabular}{|c|c|c|c|c|c|c|}
\hline & Baseline & $\begin{array}{l}\text { First } \\
\text { Shift }\end{array}$ & $\begin{array}{l}\text { Second } \\
\text { Shift }\end{array}$ & Baseline & $\begin{array}{l}\text { First } \\
\text { Shift }\end{array}$ & $\begin{array}{l}\text { Second } \\
\text { Shift }\end{array}$ \\
\hline Animal & $15^{*}$ & $5^{*}$ & $45^{*}$ & $15^{*}$ & $45^{*}$ & $5^{*}$ \\
\hline $\begin{array}{l}S 1 \\
S 2\end{array}$ & $\begin{array}{l}2.4 \\
1.9\end{array} \dagger$ & $\begin{array}{l}1.1 \\
0.6\end{array}$ & $\begin{array}{r}1.5 \\
+\quad 2.8\end{array}$ & & & \\
\hline $\begin{array}{l}\text { S3 } \\
\text { S4 }\end{array}$ & & & & $\begin{array}{l}3.6 \\
5.4\end{array}$ & $\begin{array}{l}3.3 \\
2.6\end{array}$ & $\begin{array}{l}\dagger \\
\dagger \quad 0.0 \\
\dagger \quad 0.8\end{array}$ \\
\hline
\end{tabular}

Note-Half-life is average time (in seconds) for selected behaviors to attain half their maximal rate. Data are averaged over five-session blocks. Baseline block includes last five sessions; shift conditions include Sessions 6-10. *FT in green. †Pairs whose differences are significant $(p<.05)$

tive one, with its focus on the nature and distribution of adjunctive behaviors that are embodied in Figure 1.

The pigeons were held at the shifted values for 55 sessions to ascertain whether there would be a continued recalibration of the criterion count as evidenced by a recovery in the average half-life. This was the case for 3 out of the 4 birds, as evaluated by matched $t$ tests. For both birds shifted to the 5-sec FT, mean HL increased over the course of this condition, from 0.6 to $2.6 \mathrm{sec}$ (S1, $p<.05$ ) and from 1.1 to $1.8 \mathrm{sec}(\mathrm{S} 2$, n.s.). For both birds shifted to $45-\mathrm{sec}$ FT, mean HL decreased, from 3.3 to $2.4 \mathrm{sec}$ $(\mathrm{S} 3, p<.01)$ and from 2.6 to $1.7 \mathrm{sec}(\mathrm{S} 4, p<.01)$.

\section{DISCUSSION}

This experiment provides only circumstantial support for the hypothesis that the speed of the pacemaker depends on more than the local context of reinforcement. Those animals first shifted to a lower overall rate of reinforcement (FT $45 \mathrm{sec}$ ) did not shift in the predicted direction. This contretemps may have been due in part to our choice of the second five sessions after a shift as the data base. We chose this time as long enough after the shift for the pacemaker to have adjusted, but not so long that there would be much reconditioning of the criterion number of pulses required to enter the various states. In the case of the FT 45 sec condition, however, the half-lives continued to increase through Sessions 11-15 postshift.

The use of half-life, rather than direct estimation of $\tau$, removes us one step from the (hypothetical) controlling variable and risks the confound of changes in criterion number of pulses compensating for changes in $\tau$. Halflife was chosen as our dependent variable because it was more theory-neutral and required fewer parameter estimates. Fitting the model (Equation 1) to data such as those shown in Figure 1 would require 3 parameters for each behavior (criterion number of pulses to enter the state, number to exit, and a scale factor for the arbitrary response units) plus the parameter, $\tau$, that would serve all behaviors. This analysis was conducted for Animal S1 in baseline and first shift condition. Appropriate parameter values were estimated for each behavior in each condition, and these estimates were used as seeds in a program that assumed a common value for $\tau$ within each condition and common values of the other 3 parameters for the same behavior across conditions. For Animal S1, for whom six behaviors were observed, this required 20 parameters for the $\mathbf{1 8 0}$ data points. The solution eventually converged to account for $99 \%$ of the data variance. The 2 parameters of interest were $\tau$ in the baseline condition and $\tau$ in the 5 -sec condition; they were 0.84 and $0.57 \mathrm{sec}$, and thus showed the expected shift. This analysis provides a much more efficient use of the data to estimate clock speeds. However, the program must be nursed along toward convergence, and uniqueness of the solution cannot be guaranteed. Furthermore, in some cases the scale factors associated with some of the behaviors appear to change from one condition to the next. If those behavior-specific parameters cannot be held constant between conditions, some of the advantages of this approach will be undermined. In the present case, however, the analysis does provide some validation of the half-life as an index of clock speed.

There is a long history of research on multiple schedules of reinforcement that demonstrates an interaction between rate of reinforcement in one of the components and rate of behavior in the other component (Staddon, 1977). Williams and Wixted (1986) have suggested that response rate is proportional to reinforcement rate relative to a weighted average of reinforcement rates in all components of the multiple schedule. In like manner, we believe that the speed of an animal's pacemaker depends on the average rate of reinforcement in its environment. That environment is now seen to include alternate components of multiple schedules. Time-out may also be included in that context, although insofar as it is a radically different environment (e.g., complete blackout, removal from the apparatus, etc.), the contribution may be minimally weighted. The relation of the behavioral theory of timing to theories of contrast remains inchoate. It is possible, however, that the speed of an animal's pacemaker is the 
variable that embodies the weighted average ("adaptation level') rate of reinforcement, against which the expectations in local contexts are evaluated.

Variations in the speed of the pacemaker because of events "elsewhere" would wreak havoc on refined temporal discriminations unless there were a mechanism available to compensate for such shifts. For the scalar expectancy theory (Gibbon, 1977), the overall expectancy of reward cancels out of the expectancy ratios, and it is the latter which control timing. For the behavioral theory of timing, when a particular adjunctive behavior no longer is a reliable signal because its distribution has been shifted, it will extinguish as a conditioned stimulus and other, more temporally appropriate behaviors will take over. We have provided some evidence for such disruption and subsequent recalibration of adjunctive behaviors.

\section{REFERENCES}

Anderson, M. C. , Shettleworth, S. J. (1977). Behavioral adaptation to fixed-interval and fixed-time food delivery in golden hamster. Journal of the Experimental Analysis of Behavior, 25, 33-49.

Church, R. M. (1984). Properties of the internal clock. In J. Gibbon \& L. Allen (Eds.), Annals of the New York Academy of Sciences: Vol. 423. Timing and time perception (pp. 556-582). New York: New York Academy of Sciences.

Fetterman, J. G., Killeen, P. R. (1991). Adjusting the pacemaker. Learning and Motivation, 22, 226-252.
GibBon, J. (1977). Scalar expectancy theory and Weber's law in animal timing. Psychological Review, 84, 277-325.

GibBoN, J. (1986). The structure of subjective time: How time flies In G. H. Bower (Ed.), The psychology of learning and morivation (Vol. 20, pp. 105-135). New York: Academic Press.

HAKGHT, P. A. (1989). Timing and the organization of adjunctive behavior Unpublished master's thesis, Arizona State University, Tempe, AZ.

Hartman, D. P. (1977). Considerations in the choice of interobserver reliability estimates. Journal of Applied Behavior Analysis, 10, 103-116.

Killeen, P. R. (1979). Arousal: Its genesis, modulation, and extinction. In M. D. Zeiler \& P. Harzem (Eds.), Advances in the analysis of behavior: Reinforcement and the organization of behavior (Vol. 1, pp. 169-216). Lincoln: University of Nebraska Press

KILLEeN, P. R. (1991). Behavior's time. In G. Bower (Ed.), The psychology of leaming and motivation (Vol. 27, pp. 295-334). New York: Academic Press.

KilleEn, P. R., Fetterman, J. G. (1988). A behavioral theory of timing. Psychological Review, 95, 274-295.

ReberG, D., InNis, N. K., MANN, B., Eizenga, C. (1978). Superstitious behavior resulting from periodic response-independent presentations of food or water. Animal Behaviour, 26, 507-519.

StadDon, J. E. R. (1977). Schedule-induced behavior. In W. K. Honig and J. E. R. Staddon (Eds.), Handbook of operant behavior (pp. 125 152). Englewood Cliffs, NJ: Prentice-Hall

Staddon, J. E. R., Simmelhag, V. L. (1971). The "superstition" experiment: A reexamination of its implications for the principles of adaptive behavior. Psychological Review, 78, 3-43.

WILliams, B. A., WIXTED, J. T. (1986). An equation for behavioral contrast. Joumal of the Experimental Analysis of Behavior, 45, 47-62.

(Manuscript received October 26, 1989; revision accepted for publication February 20, 1991.) 